\title{
Isolated Intraventricular Hemorrhage Associated with Cerebral Vasospasm and Delayed Cerebral Ischemia following Arteriovenous Malformation Rupture
}

\author{
Krishna Amuluru a, c Fawaz Al-Mufti ${ }^{b}$ d Charles E. Romero ${ }^{c}$ \\ Chirag D. Gandhi ${ }^{a, d}$ \\ a Department of Neurosurgery and Neuroscience, New Jersey Medical School, Rutgers \\ University, Newark, NJ, USA; ${ }^{b}$ Division of Neuroendovascular Surgery and Neurocritical \\ Care, Neurology, Rutgers Robert Wood Johnson Medical School, New Brunswick, NJ, USA; \\ 'Department of Interventional Neuroradiology, University of Pittsburgh Medical Center - \\ Hamot, Erie, PA, USA; d Department of Neurosurgery and Neurocritical Care, Westchester \\ Medical Center at New York Medical College, Valhalla, NY, USA
}

\section{Keywords}

Arteriovenous malformation · Cerebral vasospasm - Delayed cerebral ischemia ·

Intraventricular hemorrhage $\cdot$ Stroke $\cdot$ Subarachnoid hemorrhage $\cdot$ Vasospasm

\begin{abstract}
Background: Although it is well characterized in aneurysmal subarachnoid hemorrhage, vasospasm is exceedingly rare following cerebral arteriovenous malformation (AVM) rupture. Subsequently, this complication is poorly characterized with regard to delayed cerebral ischemia (DCl). We review cases of ruptured AVM to assess the frequency and severity of vasospasm on cerebral angiography, and DCl. Summary: We reviewed our institutional database of acute intracranial hemorrhages between 2005 and 2014. We identified patients with cerebral AVM rupture and evidence of vasospasm, which was confirmed with digital subtraction angiography (DSA). Cerebral angiograms were evaluated by 2 blinded neurointerventionalists for vasospasm. Statistical analyses were conducted on the angiographic results and variables of interest to determine predictors and associations of vasospasm and $\mathrm{DCl}$. Thirty-six patients with acute intracranial hemorrhage due to ruptured cerebral AVM subsequently underwent cerebral angiography. The interrater reliability for vasospasm was 0.81 . The incidence of vasospasm was $13.9 \%$ and the incidence of subsequent DCI was $11.1 \%$. A significant relationship
\end{abstract}

This work was presented as an oral abstract at the Society of Neurointerventional Surgery (SNIS) 13th Annual Meeting on July 25-28, 2016, in Boston, MA, USA 
existed between isolated intraventricular hemorrhage and vasospasm $(p=0.001)$ and subsequent $\mathrm{DCl}(p=0.006)$. Radiographic vasospasm was associated with $\mathrm{DCl}$ in $80 \%$ of the patients $(p<0.0001)$. No statistical significance existed between subarachnoid hemorrhage and the development of vasospasm or $\mathrm{DCl}(p=1.000$ and $p=0.626$, respectively). All differences were significant at a $99 \%$ level of significance. Key Message: In cases of ruptured AVM, isolated intraventricular hemorrhage appears to be an independent risk factor for vasospasm and DCI. Vasospasm must be considered during late neurological deterioration following AVM hemorrhage, especially in the setting of isolated intraventricular hemorrhage.

(c) 2018 S. Karger AG, Basel

\section{Introduction}

Vasospasm is a well-known and detrimental complication present in up to $70 \%$ of cases of aneurysmal subarachnoid hemorrhage (SAH) [1]. Although it is well characterized in aneurysmal $\mathrm{SAH}$, vasospasm is exceedingly rare following hemorrhage of an arteriovenous malformation (AVM). Fifty percent of patients with AVM present with hemorrhage; however the reported rates of cerebral vasospasm following rupture are very low [2]. As a result, this severe complication has been described only a few times in the literature and is poorly characterized with respect to its management.

There have only been 15 reports on 29 patients sustaining radiographic vasospasm after AVM rupture [2-14]. Additionally, information on the means by which vasospasm was detected and the incidences of delayed cerebral ischemia (DCI) and cerebral infarction were not provided in all of these series.

In this article, we review our own cases of ruptured AVM to assess the frequency and severity of vasospasm in this patient population as documented by cerebral digital subtraction angiography (DSA). We also sought to assess the clinical significance of vasospasm after AVM rupture by determining its frequency, and its association with both DCI and cerebral infarction.

\section{Materials and Methods}

Study Population and Data Collection

We retrospectively reviewed our institutional database of intracranial hemorrhage and identified patients with radiographic evidence of hemorrhage secondary to cerebral AVM who subsequently received diagnostic cerebral DSA during the same admission between September 2005 and May 2014. This study was approved by the institutional review board. Written informed consent for all of the procedures was obtained from the patients or their legal guardians.

We enrolled patients with intraparenchymal hemorrhage (IPH), intraventricular hemorrhage (IVH), and SAH. We excluded all patients with intracranial hemorrhages secondary to etiologies other than AVM rupture, such as trauma, hypertension, aneurysms that were not intranidal, amyloid angiopathy, and/or tumor. We also excluded patients with dural arteriovenous fistulae and spinal AVM. Patients without diagnostic cerebral angiography were excluded. Charts were reviewed for specific variables of interest including demographics, admission Glasgow coma scale, time between admission and diagnostic angiography, size and location of the hemorrhage, Spetzler-Martin AVM grading scale, presence of vasospasm, and presence of DCI.

\section{Clinical and Radiologic Values}

The diagnosis of intracranial hemorrhage was established based on the medical history and a noncontrast CT scan of the head on admission. A ventricular catheter was emergently placed in all patients with ventriculomegaly or IVH and a decreased level of consciousness that could not be attributed to causes other than hydrocephalus. As per our institutional protocol, all patients with intracranial hemorrhage received daily transcranial doppler exams, and those with elevated velocities underwent CT angiography to confirm 
the presence of cerebral vasospasm. In patients with elevated TCD velocities, as well as CTA suggesting the presence of vasospasm, a diagnostic cerebral angiogram was utilized for confirmation. Radiology reports were examined for the type of intracranial hemorrhage, including SAH, IVH, and IPH. In cases of IVH the implicated bleeding ventricle(s) were recorded, and in cases of IPH the size of the hematoma was recorded. Patients with noninvasive imaging highly suggestive of cerebral AVM on noncontrast CT of the head, CT angiography, or MR angiography had DSA performed during the same hospitalization. Cerebral DSA was performed to confirm the presumed diagnosis of AVM, to evaluate for high-risk features that would necessitate acute treatment (such as intranidal aneurysms and venous stenosis), or in some cases to evaluate clinical deterioration thought to be secondary to cerebral vasospasm.

All angiograms were independently reviewed for vasospasm by 2 neurointerventional surgeons, both of whom were blinded to the radiology reports and clinical data. The presence of vasospasm was established solely by diagnostic cerebral angiography. Electronic medical records, and laboratory data; all related noninvasive imaging and angiographic data of the patients were reviewed.

Outcome Assessment

All patients with ruptured AVM had at least 3 weeks of formal clinical neurologic follow-up to assess for clinical change. The primary measurements of outcome were the development of cerebral vasospasm as evident on DSA, and the development of DCI, which was defined as: (1) clinical deterioration (i.e., a new focal deficit, a decrease in the level of consciousness, or both) and/or (2) a new infarct on CT or MRI that was not visible on the admission scan, when the cause was thought by the research team to be due to vasospasm. If patients demonstrate clinical and radiographic evidence of cerebral vasospasm, hyperdynamic therapy is initiated, with reservation of intra-arterial therapy for patients who are unresponsive to aggressive medical management.

\section{Statistical Analyses}

The interobserver agreement was measured using a weighted $\kappa$ [15]. We performed descriptive statistics, multiple $\chi^{2}$ tests, and Fisher's exact test to determine if any of the variables had a significant correlation with the occurrence of vasospasm or DCI posthemorrhage. $p<0.05$ was considered statistically significant. Statistical analysis was performed using SAS (v9.4; SAS Institute, Cary, NC, USA) and SPSS 22.0 (v22.0; IBM, Armonk, NY, USA).

\section{Results}

We identified 854 patients presenting to our institution with ICD-9 and ICD-10 codes for intracranial hemorrhage between September 2005 and May 2014. Thirty-six patients with acute intracranial hemorrhage diagnosed with ruptured cerebral AVM underwent a subsequent cerebral angiography. All patients received a subsequent angiogram during the same admission, and thus no patients were excluded for not having catheter angiography. The average time between ictal hemorrhage and DSA was 2.5 days (range 0-12 days). The interrater reliability for vasospasm, measured using the weighted $\kappa$ statistic, was 0.81 .

\section{Frequency and Demographics}

Five patients demonstrated radiographic vasospasm, resulting in an incidence of 13.9\%; 4 patients subsequently developed DCI, resulting in an incidence of $11.1 \%$ (Table 1 ). There was no statistically significant difference between the groups of patients who developed vasospasm and those who did not, in terms of demographics, past medical history, AVM characteristics or hemorrhage characteristics (Table 1). Nidal aneurysms were discovered in 8 patients, 3 of whom had an element of SAH. None of the patients with nidal aneurysms had isolated SAH. There was no statistically significant association between the presence of nidal aneurysms and either vasospasm or DCI. Radiographic vasospasm was associated with the development of DCI in $80 \%$ of the patients $(p<0.0001)$. 
Table 1. Ruptured arteriovenous malformation in the patient population and patient subgroups

\begin{tabular}{|c|c|c|c|c|c|}
\hline & $\begin{array}{l}\text { All ruptured } \\
\text { AVM }\end{array}$ & $\begin{array}{l}\text { Ruptured } \\
\text { AVM without } \\
\text { vasospasm }\end{array}$ & $\begin{array}{l}\text { Ruptured } \\
\text { AVM with } \\
\text { vasospasm }\end{array}$ & $\begin{array}{l}\text { Ruptured } \\
\text { AVM with } \\
\text { DCI }\end{array}$ & $p$ value ${ }^{*}$ \\
\hline \multicolumn{6}{|l|}{ Demographics } \\
\hline Total patients & 36 & $31(86)$ & 5 (13.9) & $4(11.1)$ & \\
\hline Mean age, years & 43 & 40 & 62 & 56 & 0.0757 \\
\hline Male sex & $20(56)$ & $17(55)$ & $3(60)$ & $3(75)$ & 1.0000 \\
\hline Female sex & $16(44)$ & $14(45)$ & $2(40)$ & $1(25)$ & \\
\hline Smoking history & $4(11)$ & $2(6)$ & $2(40)$ & $1(25)$ & 0.6750 \\
\hline \multicolumn{6}{|l|}{ AVM characteristics } \\
\hline Supratentorial & $27(75)$ & $24(77)$ & $3(60)$ & $3(75)$ & 0.5810 \\
\hline Infratentorial & $10(28)$ & $8(26)$ & $2(40)$ & $1(25)$ & 0.6034 \\
\hline Superficial drainage & $18(50)$ & $15(48)$ & $3(60)$ & $2(50)$ & 1.0000 \\
\hline Deep drainage & $16(44)$ & $14(45)$ & $2(40)$ & $2(50)$ & 1.0000 \\
\hline Intranidal aneurysm & $10(28)$ & $8(26)$ & $2(40)$ & $2(50)$ & 0.6034 \\
\hline SM grade 1 & 7 (19) & $7(19)$ & 0 & 0 & 0.5590 \\
\hline SM grade 2 & 7 (19) & $5(16)$ & $2(40)$ & $1(25)$ & 0.2440 \\
\hline SM grade 3 & $15(42)$ & $13(42)$ & $2(40)$ & $2(50)$ & 1.0000 \\
\hline SM grade 4 & $1(3)$ & 0 & 0 & 0 & 1.0000 \\
\hline SM grade 5 & $3(8)$ & 0 & 0 & 0 & 1.0000 \\
\hline \multicolumn{6}{|c|}{ Intracranial hemorrhage characteristics } \\
\hline Any IPH & $27(75)$ & $26(84)$ & $1(20)$ & 0 & 0.0094 \\
\hline Isolated IPH & $6(17)$ & $5(16)$ & 0 & 0 & 1.0000 \\
\hline Any SAH & $15(42)$ & $13(42)$ & $2(40)$ & $1(25)$ & 1.0000 \\
\hline Isolated SAH & $1(3)$ & $1(3)$ & 0 & 0 & 1.0000 \\
\hline Any IVH & $26(72)$ & $21(68)$ & $5(100)$ & $4(100)$ & 0.2931 \\
\hline Isolated IVH & $3(8)$ & $0(0)$ & $3(60)$ & $3(75)$ & 0.0014 \\
\hline
\end{tabular}

Values are presented as numbers or numbers (\%). Percentages denote the percent of patients with a particular feature presenting with hemorrhage. AVM, arteriovenous malformation; DCI, delayed cerebral ischemia; IPH, intraparenchymal hemorrhage; IVH, intraventricular hemorrhage; SAH, subarachnoid hemorrhage; SM, Spetzler-Martin. ${ }^{*} p$ values for binary variables were determined using the $\chi^{2}$ test and the $t$ test for continuous variables. $p$ values were calculated for ruptured AVM with vasospasm vs. ruptured AVM without vasospasm.

\section{Demographics of Vasospasm Cases}

Of the 5 patients with vasospasm, 3 had supratentorial AVM, while 2 had infratentorial lesions. Of the supratentorial AVM, 1 patient developed vasospasm of the supraclinoid right internal carotid artery, while the other 2 developed vasospasm of the distal circle of Willis vessels. Of the 2 infratentorial AVM, 1 patient developed vasospasm of the basilar artery, the right vertebral artery, and the anterior spinal artery, while the other patient developed vasospasm of the left superior cerebellar artery. None of the 5 patients with vasospasm required intervention for vasospasm treatment. Of the 5 patients with vasospasm, 2 were discharged with a modified Rankin scale score of zero, 2 were discharged with a modified Rankin scale score of 1 , and 1 patient died during the hospitalization due to complications from the hemorrhage. Two patients went on to receive subsequent embolization, 1 patient received embolization followed by stereotactic radiosurgery, and 1 patient's AVM was conservatively monitored. 


\section{Timing of Vasospasm and DCI}

The mean time between ictal hemorrhage and demonstration of radiographic vasospasm was 7.4 days, with a median value of 7 days (range 1-12 days). The mean time between ictal hemorrhage and declaration of DCI was 9.5 days, with a median value of 9.5 days (range 4-15 days).

\section{IVH and Predictors of Vasospasm and DCI}

Of the 36 patients included in our cohort, $26(72 \%)$ had some component of IVH, and, of those patients, 5 developed radiographic vasospasm $(p=0.290)$. Three patients had isolated IVH, all of whom had ventricular catheters placed on admission, which were all subsequently removed within the following 5 days, without the need for permanent shunting. All patients with isolated IVH went on to develop both cerebral vasospasm and DCI ( $p=0.001$ and $p=$ 0.006 , respectively). Among these 3 patients, 2 had casting of the bilateral lateral, third, and fourth ventricles.

We found a significant relationship between isolated IVH and vasospasm ( $p=0.001)$ as well as the development of DCI $(p=0.006)$. No statistical significance was found between IPH or SAH and the development of vasospasm or DCI ( $p=1.000$ and $p=0.626$, respectively). All differences were significant at a 99\% level of significance.

\section{Discussion}

Although it is well characterized in aneurysmal SAH, vasospasm is exceedingly rare following hemorrhage of an AVM, despite the fact that AVM rupture is a common cause of spontaneous SAH. As a result, this severe complication has been described only a few times in the literature and is poorly characterized with respect to its management. We reviewed our own series of ruptured AVM to assess the frequency and severity of vasospasm in order to elucidate the diagnosis and management of this potentially underdiagnosed entity.

Cerebral vasospasm is present in up to $70 \%$ of aneurysmal SAH, and it is most severe 5-14 days after bleeding, with resolution within 2-3 weeks [10]. The pathophysiology responsible for cerebral vasospasm remains a topic of fervent debate. However, there is a general consensus that spasmogenic and neuroinflammatory substances generated from the lysis of subarachnoid blood propagates the process [16]. Other prevailing etiological theories include a decreased response to nitric oxide, an increased sensitivity to the vasoconstrictor endothelin, and inactivity of potassium channels $[13,17,18]$.

In our cohort, there was a 13.9\% incidence of radiographic vasospasm after AVM rupture, which is consistent with previously reported incidence rates between 2 and $31 \%$ [2, 10, 19]. This finding is in stark contrast to the $70 \%$ rate of vasospasm cited in cases of aneurysmal SAH. Although the reason behind this incongruity is currently unknown, theoretical differences in hemodynamic pressure of the blood when entering the subarachnoid space may be responsible [10]. The blood from aneurysmal SAH gains immediate and high-pressure access to the subarachnoid space and may immediately initiate cell-mediated responses to the point of inciting vasoconstriction. In contrast, the low hemodynamic pressure of AVM hemorrhages, and the lack of exposure of the subarachnoid vessels to the intraparenchymal or intraventricular hemolytic products, may not provoke the same cell-mediated response to incite vasospasm $[10,14]$. Furthermore, the presence of hemorrhagic products around the circle of Willis is rare since the majority of AVM are peripherally or deeply situated and AVM bleeds are commonly less severe than aneurysmal SAH. While some cases of AVM rupture and subsequent vasospasm and/or DCI may be attributable to SAH due to ruptured nidal aneurysms, none of the patients in our cohort who developed either vasospasm or DCI demonstrated such nidal aneurysms. 
Although $42 \%$ of our cohort (15 out of 36 patients) demonstrated some component of $\mathrm{SAH}$, we found no statistical significance between SAH and the development of vasospasm or DCI ( $p=1.000$ and $p=0.626$, respectively). The presence of SAH does not always lead to vasospasm, whether in trauma or in spontaneous cases, and thus other mechanisms may be implicated in its development [20,21]. Furthermore, several studies have reported cases of AVM rupture and subsequent symptomatic vasospasm in the complete absence of SAH $[2,7,8]$. Posttraumatic vasospasm has also been demonstrated in patients without any detectable $\mathrm{SAH}$, thought to be due to stretching and pulling forces exerted on the cerebral vasculature $[22,23]$. Vasospasm in patients with AVM rupture may thus be related, in some part, to mechanical stretching on the cerebral vasculature by the mass effect of the AVM nidus. In addition, poor clearance of cerebrospinal fluid has been proposed as a contributor to stasis of potentially spasmogenic material in cases of vasospasm after AVM rupture without SAH [7]. These theories may explain why there was no significant association between SAH and cerebral vasospasm or DCI in our cohort. Thus, it is possible that the presence of SAH is not as critical a variable in the prediction of vasospasm and/or DCI in ruptured AVM cases compared to spontaneous or aneurysmal SAH cases.

IVH has been shown by several large reports to be an independent predictor of both delayed vasospasm and DCI $[24,25]$. A hypothetical mechanism of vasospasm following isolated IVH involves a constant recirculation of heme products into the subarachnoid space with subsequent propagation of cell-mediated responses $[13,26]$. Additionally, a large amount of IVH may delay cerebrospinal fluid circulation and inhibit the washout of hemorrhagic fluid, thus provoking continuous cerebrovascular stimulation, resulting in delayed vasospasm. Although it is possible that IVH may promote proximal arterial spasm, adverse effects on cerebral blood flow or tissue tolerance for ischemia may also increase susceptibility to DCI. In their seminal report, Claassen et al. [24] showed that the presence of any ventricular blood predisposes to DCI, and the risk is highest when blood is present in both lateral ventricles, thus proposing a new radiographic classification scheme of SAH. IVH in animal models has been shown to cause worsening spasm, periventricular blood infiltration, extensive ependymal disruption, cellular desquamation, and subependymal gliosis. Injury of this type in brain regions adjacent to ventricular blood may exacerbate ischemia or adversely affect the cerebral microcirculation [26, 27]. All of the patients in our cohort who developed cerebral vasospasm and cerebral infarction had a component of IVH, and isolated IVH demonstrated a significant correlation with vasospasm $(p=0.001)$ and DCI $(p=0.006)$. Because all of our patients with acute hydrocephalus and a depressed level of consciousness were treated with ventricular drainage, a reduced cerebral perfusion pressure due to an elevated intracranial pressure does not account for the association between isolated IVH and DCI. While hypertensive thalamic and putaminal hemorrhages with IVH are very common in clinical practice, no reports exist describing vasospasm without concurrent SAH. These features suggest that some unknown factors may contribute to the development of cerebral vasospasm, and further research is required to determine such variables. While the mechanism by which IVH may increase the susceptibility to DCI remains unknown, our results show that the presence of isolated IVH is a critical factor that confers an increased risk of vasospasm and subsequent DCI in patients with AVM rupture, possibly even greater than SAH.

There have only been 15 reports on 29 patients sustaining radiographic vasospasm after AVM rupture [2-14]. In the vast majority of these cases, there was some combination of SAH, IPH, and IVH. However, among these 29 patients, only 5 cases involved AVM rupture causing isolated IVH $[6,7,10,12,13]$. Our report herein provides 3 additional cases to this cohort (Table 2). When examining these 8 cases of isolated IVH after AVM rupture, isolated IVH again appears to have a strong correlation with vasospasm, DCI, and cerebral infarction. Every single patient in the literature, including those from our series, who has had isolated IVH from 


\section{Interventional Neurology}
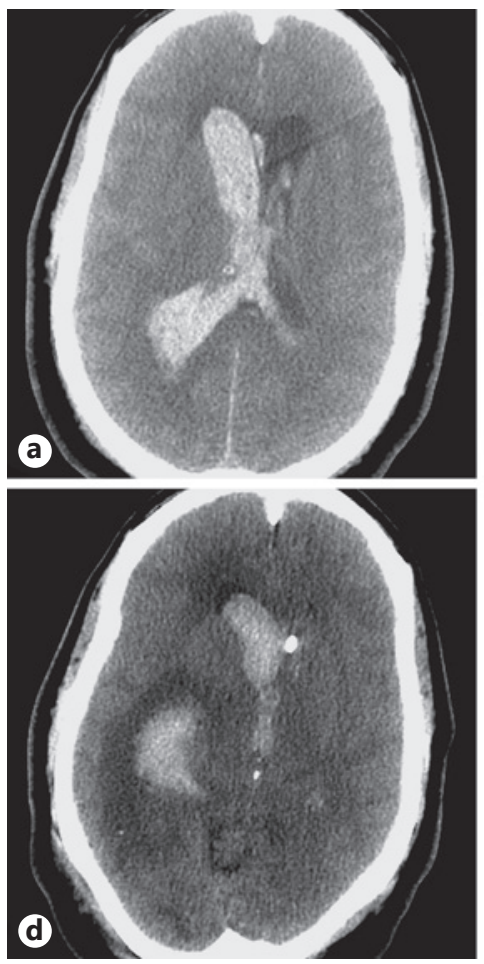

\begin{tabular}{l|l}
\hline Intervent Neurol 2018;7:479-489 \\
\hline DOI: 10.1159/000490583 & $\begin{array}{l}\text { @ 2018 S. Karger AG, Basel } \\
\text { www.karger.com/ine }\end{array}$ \\
\hline
\end{tabular}

Amuluru et al.: Isolated IVH Associated with Cerebral Vasospasm and DCI following AVM Rupture
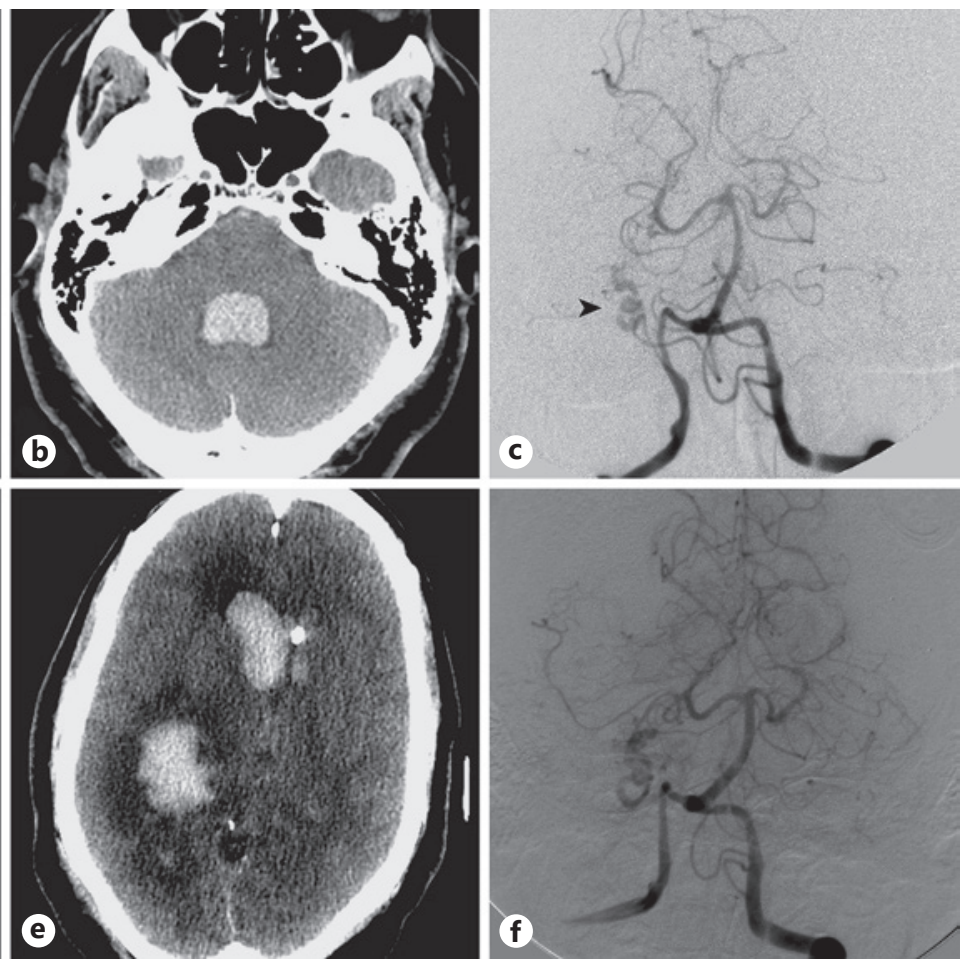

Fig. 1. This middle-aged patient presented to the emergency room obtunded. CT of the head (a, b) showed a massive isolated intraventricular hemorrhage within the bilateral lateral ventricles and the fourth ventricle. c Digital subtraction angiogram (DSA) of the left vertebral artery on postbleed day 7 shows vasospasm of the V4 segment of the right vertebral artery and the basilar artery, as well as the P2-P4 segments of both posterior cerebral arteries (PCA). Note the arteriovenous malformation (AVM) nidus and draining vein (arrowhead) drawing supply from the posterior temporal branch of the right PCA. d, e CT of the head on postbleed day 8 shows new areas of hypodensity and loss of grey-white differentiation in the bilateral occipital lobes. f Follow-up DSA 7 weeks after the hemorrhage shows resolution of the vasospasm, as well as improved opacification of the AVM nidus. The patient underwent a successful $n$-butyl cyanoacrylate (Codman, Raynham, MA, USA) embolization of the AVM.

AVM rupture has developed radiographic vasospasm (Fig. 1, 2). Additionally, every single patient subsequently developed DCI, and all but 1 patient developed cerebral infarction (Table 2).

Characteristic features of vasospasm after IVH from AVM have been previously described, including a female predominance, delayed onset, acute deterioration of consciousness, and localization to the bilateral internal carotid arteries [7,13]. However, the cases in which these features were observed included patients with concurrent SAH and IPH in addition to the IVH component. When examining the 8 cases of isolated IVH after AVM hemorrhage, there is an equal male-to-female ratio. Vasospasm onset was between the $3 \mathrm{rd}$ and the 17 th day after hemorrhage (mean: 10 days), which is typical of the onset of cerebral vasospasm after a ruptured aneurysm. Vasospasm involved both ICA in only 1 case, whereas the majority of vessels involved were the intracranial segments of the circle of Willis. In 7 out of 8 cases, vasospasm involved vessels that were not supply vessels to the AVM nidus (Table 2). It is possible that characteristic features of patients who develop vasospasm and DCI from isolated IVH after AVM rupture are different from those of patients who present with concurrent SAH, and they are vastly different from those of patients with aneurysmal SAH. Understanding these 
Interventional

Neurology

Fig. 2. This middle-aged patient presented to the emergency room with severe headache. CT of the head (a) showed an isolated intraventricular hemorrhage within the bilateral lateral ventricles (left greater than right). DSA on postbleed day 7 (b-d) of the bilateral internal carotid arteries and the left vertebral artery shows vasospasm of the proximal right anterior cerebral artery (ACA) (b), the entire left ACA (c), and the P2P3 segments of the right PCA (arrows) (d). Note the left occipitaltemporal region AVM nidus with arterial supply from the left PCA. e MRI on postbleed day 15 shows DWI intensity in the medial right frontal lobe. f, g Follow-up DSA several weeks after the hemorrhage shows resolution of the ACA and PCA vasospasm. The patient underwent successful nBCA embolization and stereotactic radiosurgery of the AVM.

\begin{tabular}{|c|c|}
\hline \multicolumn{2}{|c|}{ Intervent Neurol 2018;7:479-489 } \\
\hline DOI: $10.1159 / 000490583$ & $\begin{array}{l}\text { (c) } 2018 \text { S. Karger AG, Basel } \\
\text { www.karger.com/ine }\end{array}$ \\
\hline
\end{tabular}

Amuluru et al.: Isolated IVH Associated with Cerebral Vasospasm and DCI following AVM Rupture
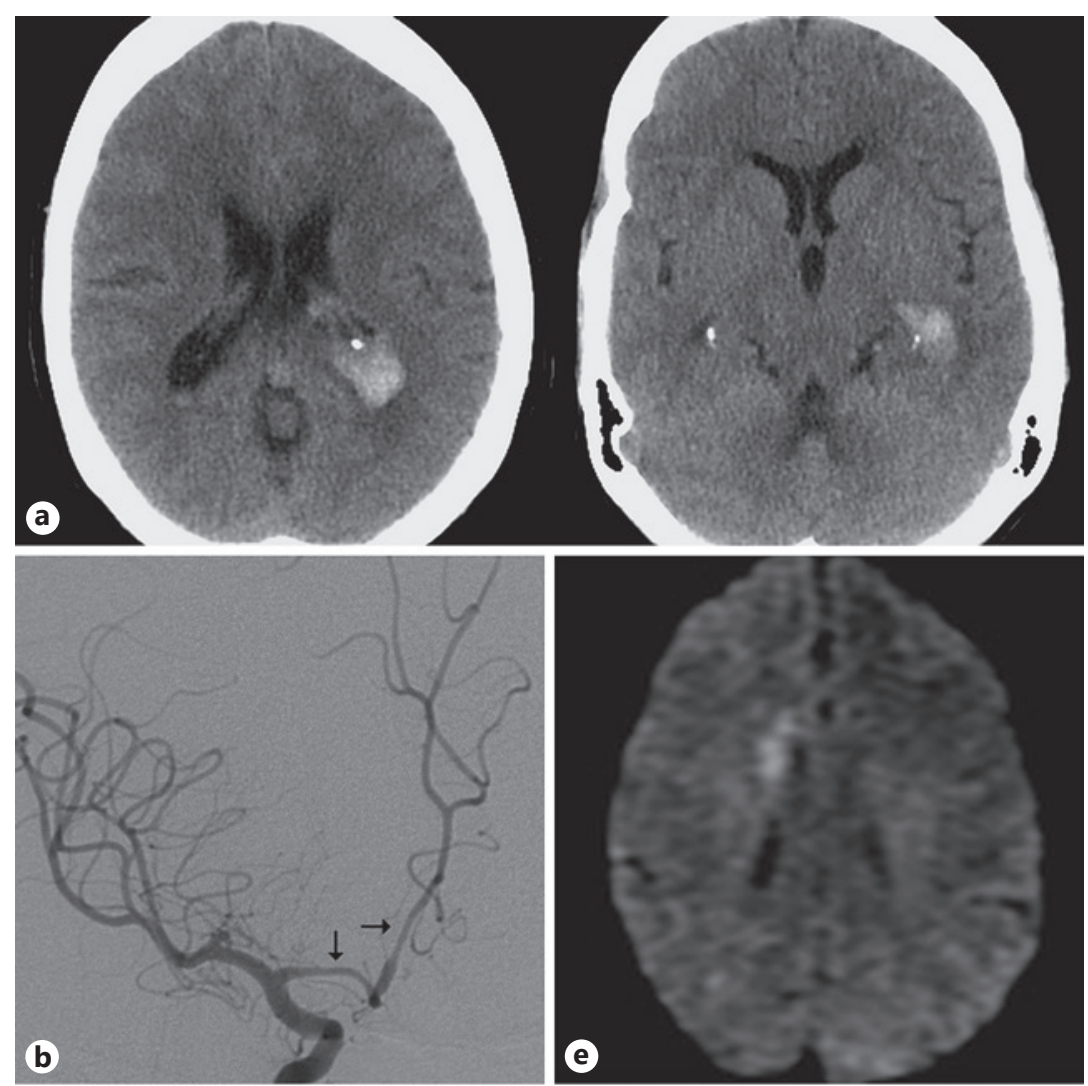

C

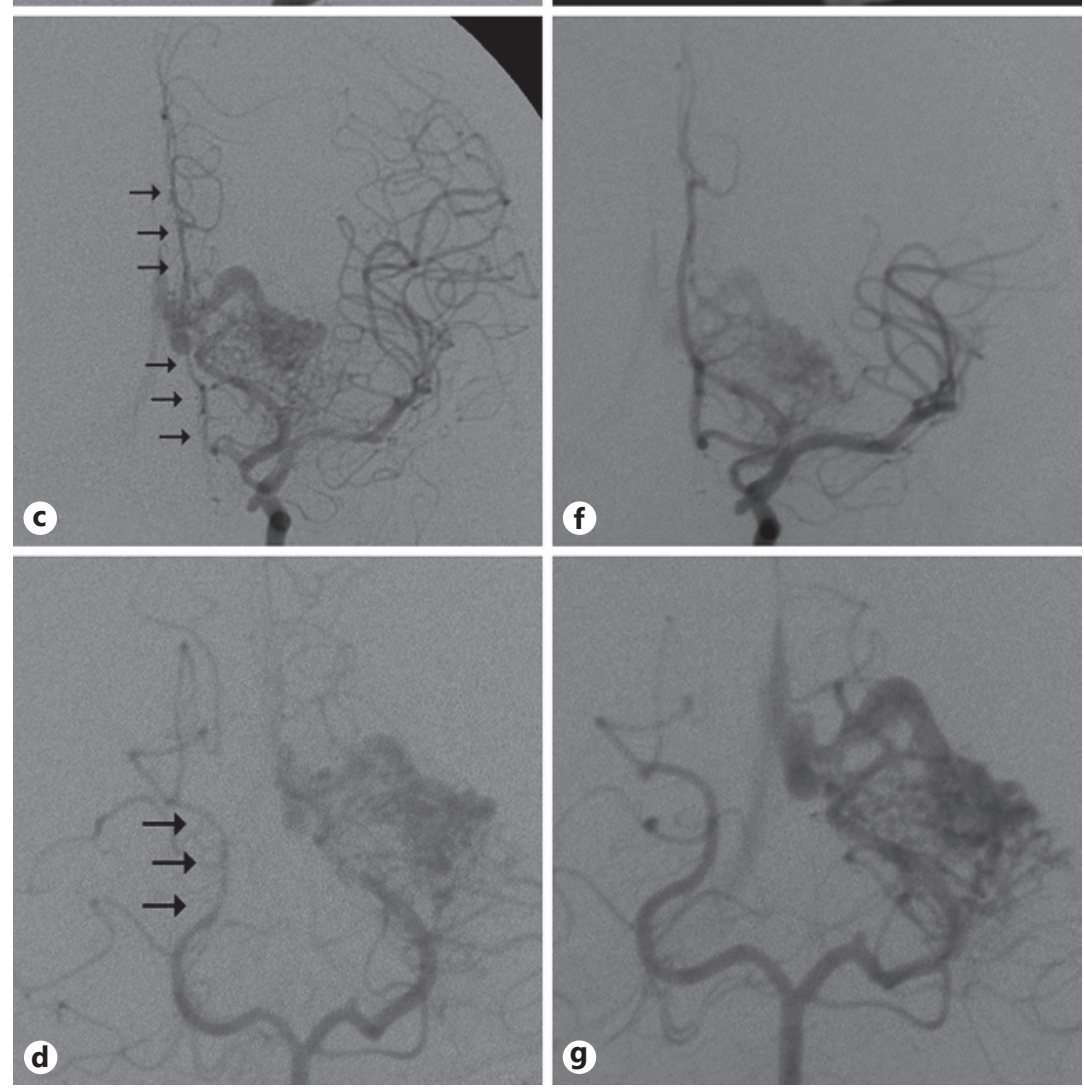


Table 2. All cases of isolated IVM after AVM rupture

\begin{tabular}{|c|c|c|c|c|c|c|c|}
\hline $\begin{array}{l}\text { Case } \\
\text { No. }\end{array}$ & Study & $\begin{array}{l}\text { Location } \\
\text { of IVH }\end{array}$ & $\begin{array}{l}\text { AVM } \\
\text { feeders }\end{array}$ & $\begin{array}{l}\text { Time between } \\
\text { the bleed and } \\
\text { DCI onset, days }\end{array}$ & $\begin{array}{l}\text { Vessels in } \\
\text { spasm }\end{array}$ & $\begin{array}{l}\text { Cerebral } \\
\text { infarct }\end{array}$ & $\begin{array}{l}\text { Clinical signs/ } \\
\text { symptoms }\end{array}$ \\
\hline 1 & $\begin{array}{l}\text { Yanaka et al. } \\
{[12]}\end{array}$ & $\begin{array}{l}\text { left lateral, } \\
\text { third, fourth }\end{array}$ & $\begin{array}{l}\text { left ACA, } \\
\text { left MCA }\end{array}$ & 3 & $\begin{array}{l}\text { bilateral A1, } \\
\text { bilateral M1 }\end{array}$ & $\begin{array}{l}\text { left parieto- } \\
\text { occipital }\end{array}$ & $\begin{array}{l}\text { right hemiparesis, } \\
\text { speech disturbance, } \\
\text { right hemianopsia }\end{array}$ \\
\hline 2 & $\begin{array}{l}\text { Kobayashi } \\
\text { et al. [7] }\end{array}$ & right lateral & right AChA & 17 & $\begin{array}{l}\text { bilateral ACA, } \\
\text { bilateral MCA }\end{array}$ & $\begin{array}{l}\text { right temporo- } \\
\text { occipital }\end{array}$ & confusion \\
\hline 3 & $\begin{array}{l}\text { Gerard et al. } \\
{[6]}\end{array}$ & $\begin{array}{l}\text { lateral, third, } \\
\text { fourth }\end{array}$ & right PCA & 10 & $\begin{array}{l}\text { bilateral MCA, } \\
\text { left ICA, } \\
\text { bilateral PCA }\end{array}$ & $\begin{array}{l}\text { left parieto- } \\
\text { occipital }\end{array}$ & $\begin{array}{l}\text { lethargy, right } \\
\text { hemineglect, right } \\
\text { homonymous } \\
\text { hemianopsia }\end{array}$ \\
\hline 4 & $\begin{array}{l}\text { Pendharkar } \\
\text { et al. [10] }\end{array}$ & $\begin{array}{l}\text { left lateral, } \\
\text { fourth }\end{array}$ & $\begin{array}{l}\text { left ACA, } \\
\text { left PCA, } \\
\text { left PChA }\end{array}$ & 6 & $\begin{array}{l}\text { bilateral ACA, } \\
\text { bilateral MCA }\end{array}$ & $\begin{array}{l}\text { left ACA } \\
\text { territory }\end{array}$ & $\begin{array}{l}\text { seizure, right } \\
\text { paresis }\end{array}$ \\
\hline 5 & $\begin{array}{l}\text { Yokobori } \\
\text { et al. [13] }\end{array}$ & $\begin{array}{l}\text { bilateral } \\
\text { lateral }\end{array}$ & left ACA & 17 & $\begin{array}{l}\text { bilateral ICA, } \\
\text { left ACA }\end{array}$ & $\begin{array}{l}\text { left frontal, } \\
\text { left parietal, } \\
\text { right occipital }\end{array}$ & $\begin{array}{l}\text { decreased motor } \\
\text { response, aphasia }\end{array}$ \\
\hline 6 & present series & $\begin{array}{l}\text { bilateral } \\
\text { lateral, third, } \\
\text { fourth }\end{array}$ & left MCA & 15 & right ICA & no & $\begin{array}{l}\text { decreased } \\
\text { executive function }\end{array}$ \\
\hline 7 & present series & $\begin{array}{l}\text { bilateral } \\
\text { lateral, third, } \\
\text { fourth }\end{array}$ & right PCA & 8 & $\begin{array}{l}\text { basilar, } \\
\text { bilateral PCA }\end{array}$ & occipital & $\begin{array}{l}\text { worsening mass } \\
\text { effect from occipital } \\
\text { infarcts }\end{array}$ \\
\hline 8 & present series & $\begin{array}{l}\text { left lateral, } \\
\text { right occipital } \\
\text { horn }\end{array}$ & left PCA & 4 & $\begin{array}{l}\text { bilateral ACA, } \\
\text { right PCA, } \\
\text { left MCA }\end{array}$ & $\begin{array}{l}\text { right ACA } \\
\text { territory }\end{array}$ & confusion \\
\hline
\end{tabular}

ACA, anterior cerebral artery; AChA, anterior choroidal artery; AVM, arteriovenous malformation; ICA, internal carotid artery; IVH, intraventricular hemorrhage; MCA, middle cerebral artery; PCA, posterior cerebral artery; PChA, posterior choroidal artery.

differences would better prepare a clinician to anticipate, recognize, and treat vasospasm and DCI in patients with ruptured AVM who do not possess the stereotypical features classically associated with vasospasm and DCI.

In one of the earliest reports on AVM rupture causing vasospasm, Yanaka et al. [12] hypothesized that vasospasm after IVH may be overlooked because patients with usual IVH are not routinely examined by catheter angiography. Prior reports have suggested that ruptured AVM with IVH could risk vasospasm only if there was associated SAH [2, 4, 7]. However, the combined data from the literature and our cohort suggests that the presence of $\mathrm{SAH}$ is not the only critical factor that confers an increased risk of vasospasm. Rather, isolated IVH is a strong independent risk factor for vasospasm and DCI.

Limitations of our study include its retrospective nature as well as the small patient population. Selection bias may exist in that we relied heavily on noninvasive imaging to identify patients with AVM. Patients with noninvasive imaging suspicious for AVM were selected to undergo catheter angiography. It is possible that patients with occult AVM, which 
were not initially evident on CTA or MRA, were inappropriately excluded from receiving DSA. During the time frame of data review, angiography was done to confirm the presumed diagnosis of AVM, to evaluate for high-risk features, or, in some cases, to further evaluate clinical deterioration thought to be secondary to cerebral vasospasm. Although our methods would identify those patients with clinically symptomatic vasospasm, angiograms performed early in a patient's hospitalization may miss cases of asymptomatic, radiographic vasospasm and thus potentially falsely lower the incidence of vasospasm.

\section{Conclusion}

We reviewed cases of ruptured AVM to assess the frequency and severity of vasospasm as documented by cerebral DSA, and its association with both DCI and cerebral infarction. The incidence of cerebral vasospasm was $13.9 \%$, while the incidence of DCI was $11.1 \%$. Isolated IVH appears to be an independent risk factor for vasospasm and DCI. Several studies, including ours presented here, have reported cases of AVM rupture and subsequent vasospasm and DCI in the complete absence of SAH, suggesting that the presence of $\mathrm{SAH}$ is not the sole factor that confers an increased risk of vasospasm. When examining all reported cases of isolated IVH after AVM rupture, isolated IVH has a strong correlation with vasospasm and DCI. The characteristic features of patients who develop vasospasm and DCI from isolated IVH after AVM rupture are different from those of patients who present with concurrent SAH and vastly different from those of patients with aneurysmal SAH. Vasospasm should be considered in cases of late neurological deterioration following AVM hemorrhage, especially in the setting of isolated IVH.

\section{Disclosure Statement}

All of the authors have no personal or institutional financial interests in the drugs, materials, or devices described in this submission.

\section{Funding Sources}

This research received no specific grant from any funding agency in the public, commercial, or not-forprofit sector.

\section{References}

1 Keyrouz SG, Diringer MN: Clinical review: prevention and therapy of vasospasm in subarachnoid hemorrhage. Crit Care 2007;11:220.

2 Maeda K, et al: Occurrence of severe vasospasm following intraventricular hemorrhage from an arteriovenous malformation: report of two cases. J Neurosurg 1997;87:436-439.

3 Gross BA, Du R: Vasospasm after arteriovenous malformation rupture. World Neurosurg 2012;78:300-305.

4 Lobato RD, Gomez PA, Alday R, et al: Vasoespasmo cerebral asociado a malformacion arteriovenosa sangrante: presentacion de cinco casos clinicos y revision de la literatura. Neurocirugia 1993;4:275-280.

5 Parkinson D, Bachers G: Arteriovenous malformations: summary of 100 consecutive supratentorial cases. J Neurosurg 1980;53:285-299.

6 Gerard E, Frontera JA, Wright CB: Vasospasm and cerebral infarction following isolated intraventricular hemorrhage. Neurocrit Care 2007;7:257-259.

7 Kobayashi M, et al: Severe vasospasm caused by repeated intraventricular haemorrhage from small arteriovenous malformation. Acta Neurochir (Wien) 2002;144:405-406. 
8 Kothbauer K, et al: Severe symptomatic vasospasm after rupture of an arteriovenous malformation. AJNR Am J Neuroradiol 1995;16:1073-1075.

9 Nishimura K, Hawkins TD: Cerebral vasospasm with subarachnoid hemorrhage from arteriovenous malformation of the brain. Neuroradiology 1975;8:201-207.

10 Pendharkar AV, et al: Successful treatment of severe cerebral vasospasm following hemorrhage of an arteriovenous malformation: case report. J Neurosurg Pediatr 2009;4:266-269.

11 Sasaki T, Mayanagi Y, Yano H, Kim S: Cerebral vasospasm with subarachnoid hemorrhage from cerebral arteriovenous malformations. Surg Neurol 1981;16:183-187.

12 Yanaka K, et al: Symptomatic cerebral vasospasm after intraventricular hemorrhage from ruptured arteriovenous malformation. Surg Neurol 1992;38:63-67.

13 Yokobori S, et al: Cerebral vasospasms after intraventricular hemorrhage from an arteriovenous malformation: case report. Neurol Med Chir (Tokyo) 2010;50:320-323.

14 Zubkov AY, Lewis AI, Scalzo D: Transluminal angioplasty and intra-arterial papaverine for the treatment of cerebral vasospasm after ruptured arteriovenous malformations. Surg Neurol 1999;51:75-79, discussion 80.

15 Viera AJ, Garrett JM: Understanding interobserver agreement: the kappa statistic. Fam Med 2005;37:360-363.

16 Provencio JJ, Vora N: Subarachnoid hemorrhage and inflammation: bench to bedside and back. Semin Neurol 2005;25:435-444.

17 Faraci FM, Heistad DD: Regulation of the cerebral circulation: role of endothelium and potassium channels. Physiol Rev 1998;78:53-97.

18 Zuccarello M, et al: Relaxation of subarachnoid hemorrhage-induced spasm of rabbit basilar artery by the $\mathrm{K}^{+}$ channel activator cromakalim. Stroke 1996;27:311-316.

19 Matsumori K, et al: Cerebral vasospasm following subarachnoid hemorrhage in arteriovenous malformation. No Shinkei Geka 1983;11:829-834.

20 Zubkov AY, et al: Risk factors for the development of post-traumatic cerebral vasospasm. Surg Neurol 2000; 53:126-130.

21 Vajramani GV, et al: Evaluation of posttraumatic vasospasm, hyperaemia, and autoregulation by transcranial colour-coded duplex sonography. Br J Neurosurg 1999;13:468-473.

22 Zurynski YA, Dorsch NW: A review of cerebral vasospasm. 4. Post-traumatic vasospasm. J Clin Neurosci 1998; 5:146-154.

23 Perrein A, et al: Cerebral vasospasm after traumatic brain injury: an update. Minerva Anestesiol 2015;81: 1219-1228.

24 Claassen J, et al: Effect of cisternal and ventricular blood on risk of delayed cerebral ischemia after subarachnoid hemorrhage: the Fisher scale revisited. Stroke 2001;32:2012-2020.

25 Frontera JA, et al: Prediction of symptomatic vasospasm after subarachnoid hemorrhage: the modified fisher scale. Neurosurgery 2006;59:21-27, discussion 21-27.

26 Liszczak TM, et al: Cerebral arterial constriction after experimental subarachnoid hemorrhage is associated with blood components within the arterial wall. J Neurosurg 1983;58:18-26.

27 Miyagami M, et al: Experimental and clinical studies on prognosis deteriorating factors in the acute stage of intraventricular hemorrhage. Neurol Med Chir (Tokyo) 1981;21:75-83. 